\section{O exílio africano de Paulo Farias (África Ocidental, 1964-1969)}

\section{Luiza Nascimento dos Reis [*]}

[*]Universidade Federal de Pernambuco — Recife (PE), Brasil.E-mail: nrluizaprof@gmail.com

ORCID: https://orcid.org/0000-0002-9859-8121
Resumo: Paulo Fernando de Moraes Farias é historiador brasileiro com renomado trabalho desenvolvido no Centre of West African Studies, da Universidade de Birmingham. Sua longa trajetória de residência e pesquisa no Reino Unido se deu após anos decisivos, em que viveu em diferentes países da África Ocidental. Perseguido politicamente pela ditadura civil-militar brasileira instaurada em 1964, Farias deixou o Centro de Estudos Afro-orientais (Ceao) da Universidade Federal da Bahia (UFBA) e vinculou-se sucessivamente a diferentes instituições acadêmicas em Gana, no Senegal e na Nigéria para desenvolver pesquisa no emergente campo da história africana. Neste texto, amparado em três entrevistas concedidas por Farias e em diversas correspondências depositadas em acervos do Ceao e da Fundação Pierre Verger (FPV), discutimos os dilemas, as descobertas e os diálogos do jovem historiador em seu exílio africano entre 1964 e 1969.

Palavras-chave: Exílio; África Ocidental; Paulo Farias.

\section{The African exile of Paulo Farias (Western Africa, 1964-1969)}

\begin{abstract}
Paulo Fernando de Moraes Farias is a renowned Brazilian historian with work developed at the Centre of West African Studies at Birminghan University. His long career of residence and research in the United Kingdom came after a decisive decade in which he lived in different countries of West Africa. Persecuted politically by the Brazilian military regime established in 1964, Farias left the Center for AfroOriental Studies at the Federal University of Bahia and was successively linked to different academic institutions in Ghana, Senegal and Nigeria to develop research in the emerging field of African history. In this text, based on three interviews given by Farias and in several correspondence deposited in collections of the Center for Afro-Oriental Studies and Pierre Verger Foundation, we discussed the dilemmas, difficulties and dialogues of the young historian in his African exile between 1964 and 1969.
\end{abstract}

Keywords: Exile; Western Africa; Paulo Farias. 


\section{Uma consulta ao mestre e babalaô}

$\mathrm{E}$

m 29 de outubro de 1972, Paulo Farias redigiu uma carta para Pierre Verger (Carta de Paulo Farias para Pierre Verger, Fundação Pierre Verger [FPV], 29 out. 1972). Instalado havia três anos na Universidade de Birmingham, o historiador brasileiro recorria ao fotógrafo e etnólogo francês radicado no Brasil para uma solicitação até então incomum em sua trajetória de vida: uma consulta ao Ifá. ${ }^{1} \mathrm{O}$ pedido, cercado de confidencialidade e urgência, estava diretamente ligado ao planejamento de seu futuro:

Vejo-me agora confrontado pela necessidade de tomar certas decisões muito sérias e de tentar enxergar um pouco quais as possíveis alternativas que o futuro guarda para mim, e qual seria a maneira de comportar-me que deverei seguir de agora por diante para obter resultados satisfatórios e evitar romper os equilíbrios essenciais. (Carta de Paulo Farias para Pierre Verger, FPV, 29 out. 1972).

Nessa correspondência, não há detalhes acerca das decisões que Farias tomaria ou de a que tipo de alternativas futuras se referia. Revelava, contudo, uma plena confiança no mestre, amigo e babalaô, bem como a necessidade de sentir-se amparado por um conselho divino diante das angústias que lhe afligiam. Verger fez a consulta e respondeu poucos dias depois, recomendando paciência e sabedoria (Carta de Pierre Verger para Paulo Farias). ${ }^{2}$ Ao agradecer, aparentemente aliviado, ou, pelo menos, mais animado, Farias revelou suas aflições, "em si mesmas, vagas":

1. Gostaria de saber [...] se há ou não, à minha frente, caminhos novos, e/ou atividades novas, em que eu possa criar coisas belas, e úteis para mim e para outros. Se não os há, como manter paz dentro de mim mesmo, de modo a poder ao menos prosseguir. O que já faço? 2. Como posso gozar a vida sem causar mal aos outros? Rena [...] quer saber se viveremos sempre juntos e se teremos filhos juntos. (Carta de Paulo Farias para Pierre Verger, FPV, 7 nov. 1972).

Nessas interrogações, o professor Paulo Farias oferece pistas para suas múltiplas angústias. Há duas semanas de completar 37 anos, o historiador revelava uma inquietação pela aparente acomodação que o vínculo como professor efetivo em uma renomada universidade inglesa lhe trazia. Estaria insatisfeito com o trabalho lá desempenhado, já que sentia a necessidade de "criar coisas belas e úteis"? Seria o ambiente universitário, conhecido por suas rivalidades e disputas, o motivo para sua preocupação em não "causar mal aos outros"? Qual sua

IIfá: o oráculo, divindade que preside a adivinhação com os búzios, o destino do ser humano (Castro, 2001, p. 250). Pierre Verger, de nome ritual Fatumbi, foi um babalaô confirmado após os longos rituais realizados na Nigéria, tornando-se "vidente, olhador, sacerdote de Ifá" (Castro, 2001, p. 164).

${ }^{2}$ Essa correspondência de Verger, com detalhes de uma consulta religiosa, é um documento incomum no largo acervo desse pesquisador. Ver, entre outros, Lühning (1998-1999). 
situação com Rena Martins, cujo relacionamento há mais de uma década agora precisava de confirmação? As aflições de Farias apontadas na correspondência, aliadas à necessidade de encontrar forças para seguir, mesmo diante de uma constante ausência de paz, certamente tinham relação com uma questão central em sua vida: a condição de exilado político.

Perseguidos pela ditadura civil-militar brasileira, Paulo Farias e Rena Martins estavam fora do Brasil desde 1964. A instalação na Europa se dava após cinco anos sucessivos em diferentes países da parte ocidental do continente africano. Em Gana, no Senegal e na Nigéria, o historiador aprofundou estudos, desenvolveu pesquisa e lecionou história africana, tornando-se o primeiro especialista brasileiro nessa área. Se, por um lado, a chegada a Birmingham era o reconhecimento de sua profícua trajetória acadêmica, por outro o mantinha na angustiante condição de exilado.

Diferentemente da maioria dos estudos e depoimentos de exilados da ditadura civilmilitar brasileira que focaram especialmente as experiências de militantes políticos em países da América Latina, da Europa ou dos Estados Unidos (Cavalcanti e Ramos, 1976; Green, 2010; Yankelevich, 2011), e ampliando as considerações de Denise Rollemberg (2007, p. 14), para quem somente após a formação acadêmica na Europa exilados brasileiros ocuparam postos em países africanos, a trajetória de Paulo Farias revela dificuldades, descobertas e estratégias do jovem historiador em seu exílio africano entre os anos 1964 e 1969. Antes um desejo, depois um imperativo; sua experiência em terras africanas aqui analisada amplia o repertório de vozes de exilados brasileiros que ainda não haviam sido ouvidas, ao mesmo tempo que evidencia seu percursor trabalho de pesquisa imerso no cenário acadêmico de produção da história africana em franca expansão.

\section{Em busca de uma história revolucionária}

Paulo Fernando de Moraes Farias fez parte dos primeiros acadêmicos que integraram o Centro de Estudos Afro-orientais (Ceao) da então Universidade da Bahia, hoje Universidade Federal da Bahia (UFBA). O Ceao foi fundado em fins de 1959 pelo polivalente filólogo português Agostinho da Silva, radicado no Brasil há alguns anos, e era um local que estimulava o cenário acadêmico brasileiro em diferentes áreas do conhecimento (Silva e Agostinho, 2007). Em Salvador, acreditando ser necessário investir em relações acadêmicas com o continente africano e encontrando terreno profícuo, estimulado pelo apoio do reitor, Edgard Santos, e pela assessoria de Pierre Verger, Agostinho inaugurou o primeiro espaço acadêmico no Brasil voltado para a pesquisa em temas da história e cultura africana. Para tanto, reuniu jovens pesquisadores que vinham de diferentes disciplinas das humanidades, letras ou artes, iniciando correspondência com diferentes instituições — acadêmicas ou não —, na África e na Europa, bem como estimulou a pesquisa de campo na África e organizou biblioteca, 
cursos de línguas e palestras enquanto dialogava com o Ministério das Relações Exteriores, buscando apoio sistemático (Reis, 2015).

O surgimento do Centro baiano, o primeiro dos três centros de estudos africanos criados no Brasil entre o final dos anos 1950 e o início da década de 1960, ${ }^{3}$ está diretamente associado a um contexto internacional em que o interesse crescente em torno de temas africanos motivado pela iminente independência dos países africanos - estimulou a criação de centros de pesquisa em instituições europeias, africanas e americanas (Ferreira, 2010). Até então, as poucas instituições de pesquisa existentes focadas na África funcionavam limitadas à lógica colonial, a exemplo do Instituto Francês da África Negra (Ifan), em Dacar, Senegal, criado em 1936, e a School of Oriental and African Studies (Soas), da Universidade de Londres, Inglaterra, desde 1938, cujo "objetivo principal foi treinar funcionários coloniais e militares" (Ferreira, 2010, p. 80). Com a independência, tanto instituições já existentes reformularam suas agendas - o Ifan foi renomeado Instituto Fundamental da África Negra (1966) quanto muitas outras surgiram, como o Instituto de Estudos Africanos, da Universidade de Ibadan, Nigéria (1962), o Centre of West African Studies, da Universidade de Birmingham (1965), bem como programas de pós-graduação em estudos africanos, como aquele criado na Universidade de Wisconsin (1961), Estados Unidos.

No Brasil, o interesse pela África era estimulado pelo olhar português. Com a criação do Ceao, o diretor-fundador, Agostinho da Silva, propunha estimular a criação de centros de estudos brasileiros em países africanos, para ampliar a influência da língua portuguesa (Reis, 2015). De algum modo, tal iniciativa estava sintonizada com as diretrizes para a política externa brasileira traçadas por Adolpho Justo Bezerra de Menezes, para quem uma aproximação cultural subsidiada pela ideologia da democracia racial brasileira e consequente ausência de racismo era o principal argumento para a aproximação comercial e a influência política sobre os países africanos recém-independentes (1960). As considerações desse diplomata brasileiro embasaram — ou, segundo Dávila, aleijaram — as relações Brasil-África, incluindo as relações acadêmicas, durante as décadas seguintes (Dávila, 2011, p. 20).

Essas ponderações despertam para o fato de que nem todas as propostas de estudos africanos estavam comprometidas com uma agenda positiva, conforme alertou Roquinaldo Ferreira ao analisar o cenário norte-americano e discutir o incentivo direto do governo norte-americano em seus interesses geopolíticos (Ferreira, 2010). É preciso destacar que, desde sua institucionalização, os estudos africanos, a incluir a história africana, são objeto de diversas análises e críticas com reflexões acerca de seus conceitos e metodologias, temas, pesquisadores e suas agendas, contribuições e limites, de que destacamos as contribuições de Jacques Depelchin (2005) Paulin Hountondji (2008) e Elisio Macamo (2016).

${ }^{3}$ Além do Ceao (1959), na UFBA, surgiram o Instituto Brasileiro de Estudos Afro-asiáticos (1961), depois transformado em Centro de Estudos Afro-asiáticos, na Universidade Candido Mendes (Ucam), no Rio de Janeiro, e o Centro de Estudos Africanos (1969), na Universidade de São Paulo (USP). 
Contudo, os pesquisadores aglutinados no Centro baiano tinham perspectivas diferentes daquelas preconizadas pelo diretor e seu interesse nos países africanos sob a colonização portuguesa. Esses investigadores acabaram por focar países da África Ocidental, a exemplo da Nigéria e do Benin, refletindo uma agenda colocada a partir do estado da Bahia, interessada em descortinar suas conexões religiosas com o continente africano. Tais esforços resultaram em publicações, hoje clássicas, a exemplo de Vivaldo da Costa Lima e sua pesquisa sobre os candomblés (Lima, 2003).

Quando foi incumbido de articular o setor de estudos históricos no Ceao, nos meses finais de 1961, Paulo Farias já havia concluído o curso de medicina — profissão que nunca exerceu - , cursava história na UFBA e lecionava no Colégio Central da Bahia. A personalidade e a forma de intervenção de Agostinho da Silva, de quem guarda as melhores lembranças, foram fundamentais para convencê-lo a investir como pesquisador nesse campo de conhecimento. Seu interesse pessoal pela história da África estava relacionado com o potencial de revisão crítica da história do Brasil. Em suas palavras:

Meu interesse pela história africana nasceu de minha postura política de esquerda, isto é, da atitude crítica que eu tinha em relação à sociedade baiana è̀ sociedade brasileira em geral, e também em relação à distribuição internacional de poder. Eu entendia que a maneira como nossa sociedade estava estruturada, e a ideologia que se manifestava em quase todos os discursos nela vigentes, eram marcadas [sic] por heranças de desigualdade e de supostas justificativas dessa desigualdade. Entendia também que uma boa parte de tudo isso era herdada diretamente da escravidão; e que para combater essa herança, e o racismo que ela carregava e continuava alimentando, seria necessário uma nova visão [sic] crítica da história do Brasil e - igualmente importante ou até mais - uma nova visão crítica da história da própria África. A ideia de uma "visão crítica" refletia minha reação contra o tipo de história que era muito frequentemente ensinado na Bahia: uma história de celebração de "grandes figuras e feitos de nosso passado". Para me libertar dessa história de enaltecimentos, eu buscava uma que fosse capaz de ser subversiva, que não tivesse excessiva reverência pelas chamadas "glórias do passado", e que tivesse o poder de revelar aspectos do passado até então ignorados ou escondidos. (Farias, 2010).

Se pensarmos com o historiador norte-americano Jerry Dávila (2011, p. 68-71), nosso professor baiano de história não seria uma exceção. Maria Yedda Linhares destacou, em entrevista concedida a Dávila, que, no início dos anos 1960, havia um entusiasmo de intelectuais brasileiros, politicamente vinculados à esquerda, pela África, embora muito pouco soubessem a respeito. Para essa historiadora, uma das primeiras a ensinar história da África em uma universidade brasileira, na Universidade do Brasil, hoje Universidade Federal do Rio de Janeiro (UFRJ), e que participou de ações voltadas para a aproximação do Brasil com a África, o continente africano era visto com ingenuidade pelos intelectuais 
da época exatamente porque se sabia muito pouco a seu respeito e olhava-se para o outro lado do Atlântico, buscando resolver o problema do Brasil.

Quando perguntado sobre o início dos estudos da história africana, Farias relembra o acesso a livros que foram cruciais. O primeiro deles foi L'Afrique Noire Occidentale et Centrale (1958), do geógrafo e historiador francês Jean Suret-Canale. Farias o encomendou em 1959 pela Maison de France, instituição francesa em Salvador que aceitava encomendas de livros franceses, quaisquer fossem sua orientação (Farias, 2010). Tal informação é relevante, uma vez que o autor era filiado ao Partido Comunista Francês, reconhecido militante político anticolonialista e, à época, lecionava em Dacar, no Senegal. O livro introduziria nosso pesquisador na história de antigos impérios africanos e tratava, entre outros aspectos, da violência e da exploração promovidas pelo sistema colonial.

Uma vez no Ceao, Paulo Farias foi auxiliado por Pierre Verger. Data de 1962 o que parece ser a primeira correspondência do jovem historiador para Verger, solicitando orientações sobre o acesso a documentos no Arquivo da Bahia (Carta de Paulo Farias para Pierre Verger, FPV, 21 maio 1962). Verger lhe recomendou o livro a História dos yorubás, de Samuel Johnson (2010). "De início, achei esse texto absolutamente impenetrável. Lembro-me de ter passado horas no CEAO, lendo aquele livro e me perguntando quando é que eu ia começar a compreender aquilo [risos]" (Farias, 2007). Esse livro, escrito por um missionário anglicano nascido em Serra Leoa e com longa trajetória na Nigéria, "faz a ponte entre a África dos séculos 18 e 19 (e as tradições africanas mais antigas) e a África do século 20" (Farias, 2010). Se o conteúdo do livro lhe parecia incompreensível, naqueles idos de 1962 tornou-se um estímulo para o desenvolvimento de pesquisa, de modo que passou a cogitar seguir para a África (Farias, 2007).

Ainda em 1962, Vivaldo da Costa Lima, pesquisador do Ceao que atuava como leitor de estudos brasileiros - oferecendo cursos livres - na Universidade de Gana, além de colaborar com a embaixada brasileira recém-instalada, enviou para Farias o livro de John Fage (Correspondência de Vivaldo da Costa Lima para Waldir Oliveira, Ceao, 19 jun. 1962). Ghana: a historical interpretation (1959) era um dos resultados de uma década de pesquisa desenvolvida pelo historiador britânico na Universidade de Gana. Farias, em contato com esse cenário acadêmico ganense e estimulado por Costa Lima, passou a nutrir o interesse em cursar o mestrado no recém-criado Institute of African Studies (IAS).

Os três livros destacados, dois diretamente nas entrevistas e um na correspondência, têm relação com a trajetória acadêmica descrita por Paulo Farias nos anos seguintes: SuretCanale lhe apresentou a história de antigos reinos africanos sobre os quais se debruçaria por longos anos; Johnson o fez mergulhar nas tradições orais como formas de pensamento desenvolvidas na África Ocidental (Farias, 1993, 1996), de modo que A história dos yorubás é, ainda hoje, um dos livros aos quais é "mais chegado" (Farias, 2010); Fage tanto o apresentou à Universidade de Gana quanto foi seu diretor - e depois colega - no Centre of West African Studies, no qual Farias descreveria longa trajetória de trabalho (Farias, 2003b). 


\section{Farias e o golpe militar no Brasil (1964)}

Paulo Farias, entre 1962 e 1964, organizava o setor de estudos históricos no Ceao: dedicava-se às leituras, à obtenção de uma bolsa de estudos no exterior e preparava cursos de história africana. Estabelecia correspondência com pesquisadores dedicados à pesquisa em história africana e também asiática. ${ }^{4}$ Tratava-se de um Centro pequeno, cujas atividades estavam a cargo de profissionais em formação inicial. No início do ano 1964, destaca-se a crescente limitação de recursos financeiros nas universidades brasileiras em face das alterações orçamentárias, o que seria assunto prioritário tratado na correspondência enviada nos meses de janeiro e fevereiro por Waldir Oliveira ao reitor Albérico Fraga (Carta de Waldir Oliveira para Albérico Fraga, Ceao, 23 jan. 1964). Se, na UFBA, a vinculação e as formas de pagamento de todos seriam revistas, isso tinha impacto especial no Ceao, uma vez que suas atividades de pesquisa e intercâmbio eram marcadas por custos extraordinários, pois previam o deslocamento de pessoas para outros países e requisitava o trabalho de profissionais sem vinculação efetiva com a universidade, a exemplo dos fotógrafos ou tradutores (Carta de Waldir Oliveira para Albérico Fraga, Ceao, 23 jan. 1964).

No primeiro semestre de 1964, Albérico Fraga estaria nos meses finais do exercício de seu reitorado na UFBA, e já era conhecida sua falta de apoio às atividades do Ceao. Quando da chegada dos estudantes africanos para curso no Ceao, nos meses finais de 1961, iniciativa que inaugurava o intercâmbio formal de estudantes africanos no Brasil, foi registrado, em uma nota jornalística, um comentário racista que havia sido proferido pelo reitor ao dizer que a Bahia não precisaria de mais negros, pois já tinha o suficiente (Carta de Pierre Verger para Costa Lima, 20 out. 1961, Afro-Ásia, n. 37, p. 254, 2008). Com o golpe político em lo de abril de 1964 e a instalação de um governo de exceção, que ficaria conhecido como ditadura civil-militar, Fraga estaria fortalecido. O reitor estava ligado ao partido responsável pela instalação do novo regime político (Ferreira, 2004), que trataria logo de investigar atividades e elementos classificados como subversivos. Isso gerou um clima de suspeição, especialmente entre professores e intelectuais, uma vez que paulatinamente as pessoas foram chamadas a prestar esclarecimentos no quartel-general.

A situação ensejava cuidados, e Waldir Oliveira estava atento. Em 29 de abril de 1964, escreveu ao pesquisador Fernando Moura, na Bélgica, com quem agendava a realização de um curso no Ceao:

Quanto à possibilidade de sua vinda e da feitura de um curso entre nós, acho-a plenamente viável, apesar das grandes transformações que sofreu o Brasil nos últimos trintas dias. Apenas aconselharia ao prezado amigo evitar um curso

Consulta aos papéis de Joseph Needhan. Disponíveis em: <https://janus.lib.cam.ac.uk/db/node.xsp?id=EAD \%2FGBR\%2F1928\%2FNRI2\%2FSCC2\%2F376\%2F17;sibO=21>. Acesso em: 4 abr. 2019. 
especial sobre Angola e Moçambique, uma vez que ainda não se sabe qual será a orientação do novo governo brasileiro de referência ao problema de Portugal na África. (Carta de Waldir Oliveira para Fernando Moura, Ceao, 29 abr. 1964).

Tão logo o governo militar foi instalado, alguns professores da universidade passaram por situação vexatória, a exemplo de Milton Santos, eminente geógrafo baiano, que foi preso. Em 19 de junho, Oliveira escrevia a Pedro Moacir Maia, professor da UFBA, que atuava em Dacar:

Quanto ao Milton, continua preso e há um processo volumoso correndo contra ele, agora na justiça, no qual ele é acusado de corrupção administrativa e malversação de dinheiro público. Embora não acredite na sua culpabilidade, a carga contra ele é pesada e encaro a possibilidade de ele vir a sair a bem disto tudo com pessimismo. (Carta de Waldir Oliveira para Pedro Maia, Ceao, 19 jun. 1964).

As acusações contra Milton Santos, que justificaram a imediata demissão sem direitos trabalhistas e consequente prisão, foram evidências do tratamento dispensado aos opositores do governo. A arbitrariedade e a brutalidade dessas atitudes instauravam um clima de tensão entre todos e revelava quão fácil seria tornar-se alvo da violência do novo governo.

Antes que se completassem dois meses do novo governo, Waldir Oliveira, diretor do Ceao, foi chamado para explicar-se no quartel-general da VI Região Militar. As atividades do Centro estariam isentas de maiores suspeitas e investigação não fosse por uma consideração: "foi o professor Paulo Fernando de Moraes Farias o único a ser procurado pelas autoridades militares, estando presentemente a responder inquérito instaurado contra a sua pessoa pelo Governo Estadual da Bahia" (Carta de Waldir Oliveira para Albérico Fraga, Ceao, 25 maio 1964). Assim, o que levaria o referido professor a ser, aparentemente, o único alvo de investigação do Ceao tão logo se tenha instaurado o regime militar? Paulo Farias não compareceu mais ao Centro desde o final de abril de 1964 (Carta de Waldir Oliveira para Flávio Costa, Ceao, 30 abr. 1964).

Sob tais circunstâncias, a correspondência do Ceao anuncia a busca de uma bolsa de estudos para Paulo Farias no exterior. Em 18 de junho, Waldir Oliveira fez um pedido para Mr. Andoh, do Institute of African Studies, em Legon, Gana (Carta de Waldir Oliveira para Mr. Andoh, Ceao, 18 jun. 1964). Em 24 de junho, falaria do assunto com o embaixador de Gana no Brasil, Dr. John Jantuah (Carta de Waldir Oliveira para a Embaixada de Gana no Brasil, Ceao, 24 jun. 1964). Em 29 de junho, iria apresentá-lo ao Registrar da Universidade de Gana: "É licenciado em História, realiza excelente trabalho, adquirido no Departamento de Estudos Históricos do Centro desde 1962. Sua admissão será importante para o intercâmbio entre a Universidade da Bahia e a Universidade de Ghana" (Carta de Waldir Oliveira para a Universidade de Gana, Ceao, 29 jun. 1964). Waldir apresentava a diferentes interlocutores o candidato ao Mestrado em Estudos Africanos daquela universidade. 
Oliveira preocupava-se com Farias, pois sabia de seu posicionamento político. Paulo Farias fazia parte do grupo de intelectuais que mantinham uma "postura política de esquerda" (Dávila, 2011, p. 71) e, embora não tenha sido filiado ao Partido Comunista do Brasil, ou mencionado a palavra socialismo ou comunismo, sabemos que é sob essa categoria que se enquadravam, ou eram enquadradas, as pessoas que se posicionavam de maneira crítica em relação ao liberalismo e ao capitalismo. O depoimento de Farias refere-se a uma época de "constantes e intensos debates intelectuais na Bahia, que ocorriam em ambientes e contextos vários" (Farias, 2010). Para dimensionar os debates, Farias cita um de seus brilhantes alunos no Colégio Central: Carlos Nelson Coutinho, que se tornaria o maior estudioso no Brasil da obra de Antônio Gramsci, filósofo marxista italiano.

Segundo Farias, tão logo o regime foi instaurado, ele e outros professores do Colégio Central da Bahia foram prontamente demitidos após processo sumário na Secretaria de Segurança Pública do Estado, cuja finalidade era um expurgo de "elementos subversivos" (Farias, 2010). No mesmo período de sua demissão, foi denunciado como subversivo ao Exército por alguns professores do Colégio Central. Outra atividade contribuía para essa situação: “[...] no momento do golpe de 1964, eu era um dos coordenadores da aplicação em Salvador do método de alfabetização e conscientização criado pelo professor Paulo Freire (e tanto Paulo Freire quanto o método dele foram tratados como extremamente 'subversivos' pela ditadura)" (Farias, 2010).

A partir de lo de abril, todos aqueles que, de uma maneira ou de outra, participavam do debate acerca dos processos políticos e ideológicos no país, ou se posicionavam criticamente em relação aos rumos da sociedade brasileira, eram suspeitos em potencial e tornaram-se alvo de investigação e arbitrariedades, vide o caso da prisão de Milton Santos. Diria Farias: "subitamente [passei] da categoria de cidadão em gozo de seus direitos à categoria de 'subversivo' que podia ser a qualquer momento alvo de arbitrariedades. E, como eu, muitos outros e outras" (Farias, 2010).

Tudo isso criou um clima de terror e perseguição entre os que não compartilhavam da orientação do governo. Farias diria: "Nesse tempo eu dormia vestido, pronto para fugir a qualquer hora, viajava de ônibus meio disfarçado" (Farias, 2010). E, assim como Waldir Oliveira ou os colegas de Farias no Colégio, muitos foram chamados a depor e estimulados a apontar colegas que tivessem opinião contrária ao governo ou apenas parecessem subversivos. Naquele início de governo, as pessoas não sabiam que tipo de ações, legitimadas pelo Estado brasileiro, poderiam acontecer às pessoas que haviam se tornado alvo de processos. Muitos foram os perseguidos, exilados, presos, torturados, mortos e desaparecidos (Cavalcanti e Ramos, 1976; Arns, 1986; Gaspari, 2002; Ferreira, 2004; Motta, 2014).

Entre os professores do Colégio Central em situação semelhante à de Farias encontrava-se Rena Martins Farias, professora de história natural, e sua esposa. Ambos compartilhariam esses momentos de verdadeiro acossamento, que desembocaria na saída do país, alterando 
definitivamente suas trajetórias. Efetivar o vínculo como estudante na Universidade de Gana tornou-se o objetivo de Farias para manter-se o mais longe possível da violência e das arbitrariedades do governo brasileiro. Para conseguir atravessar o Atlântico, o casal utilizou-se de uma rede de intelectuais que, em São Paulo, colaborava na fuga de pessoasalvo da repressão militar, auxiliando-as na obtenção dos respectivos passaportes e vistos.

Tratava-se do casal Ianni (o saudoso professor Octávio Ianni da Universidade de São Paulo e a mulher dele), do casal Weffort (o sociólogo Francisco Weffort, que anos depois seria Ministro da Cultura no governo Fernando Henrique Cardoso, e Ziláh Weffort, na época casada com ele), e o casal Segall (o escritor e empresário Maurício Segall, filho do grande pintor Lazar Segall, e a atriz Beatriz Segall, que na época era casada com o Maurício). (Farias, 2010).

A viagem foi realizada em setembro de 1964 com destino a Dacar, capital do Senegal, em função de seu aeroporto que, naquele período, recebia muitos voos internacionais. Naquela cidade, receberam o apoio do professor da UFBA Pedro Moacir Maia, então adido cultural na embaixada brasileira em Dacar e leitor na Universidade de Dacar, e Claude Cros, o estudante francês residente no Senegal que havia estado no Ceao em 1961 junto à primeira leva de estudantes africanos. ${ }^{5}$ Cros, cuja estada no Brasil havia sido muito questionada e curta, havia se casado com Maria Helena, uma aluna de Rena no Colégio Central.

Farias não havia informado Waldir Oliveira a respeito da saída do Brasil, evitando que ele se tornasse cúmplice e possivelmente alvo de investigação. Contudo, seu afastamento do país não significou o rompimento dos contatos com o Centro. Ao analisar a correspondência do Ceao, encontramos mais um pedido de bolsa para Paulo Farias, enviada por Vivaldo da Costa Lima à Universidade de Gana, em 5 de agosto de 1964. Em 25 de setembro, uma correspondência de Waldir Oliveira agradecia a Mr. Andoh a concessão da bolsa de estudos, mesmo sem a garantia de um financiamento adicional (Carta de Waldir Oliveira para Mr. Andoh, Ceao, 25 set. 1964). Quem teria informado ao Ceao que Farias já estava no continente africano? Certamente, outras missivas, que não se encontram no acervo do Centro, circularam entre os professores.

Em Dacar, a dificuldade se concentraria em confirmar se a Universidade de Gana continuava disposta a recebê-lo com acomodações para sua esposa e uma pequena bolsa para garantir a sobrevivência. Não havia como saber se o contato entre o Ceao e a Universidade de Gana prosperava, e o historiador penava em busca de informações. As comunicações não se faziam com rapidez, e não havia a confirmação necessária para seguir viagem. As redes que foram utilizadas para dar conta desse impasse revelam as articulações que aproximavam

${ }^{5}$ Na primeira experiência de intercâmbio de estudantes africanos para o Brasil, articulada pelo Ceao, o governo brasileiro disponibilizou, na Universidade de Dacar, vagas para pós-graduandos. Daí a presença de Claude Cros, que tinha nacionalidade francesa e estudava na instituição (Reis, 2015). 
aqueles que, por diferentes questões, lutavam pela liberdade. Desde 1961, a maioria dos países africanos independentes manteve seu apoio aos movimentos de libertação dos países ainda sob colonização portuguesa (Dávila, 2011, p. 117-8). Gana e Senegal mantinham, respectivamente, sedes do Movimento Popular pela Libertação de Angola (MPLA) e do Partido Africano pela Independência de Guiné-Bissau e Cabo Verde (PAIGC). Membros dessas duas importantes organizações - não as únicas que estabeleceram a luta armada como enfrentamento ao domínio colonial - puderam, por exemplo, obter novos passaportes para, fugindo da perseguição portuguesa, buscar apoio em diversos outros países, incluindo o Brasil. ${ }^{6}$ Essa rede ofereceria apoio a Paulo Farias para obter a informação necessária na Universidade de Gana, de maneira discreta, sem evidenciar sua presença na África Ocidental.

Comunicaram-se (o PAIGC) com representantes do Movimento Popular pela Libertação de Angola (MPLA) que viviam em Gana, em Acra. Uma representante do MPLA teve a gentileza de ir à Universidade de Gana, ao IAS (Institute of African Studies), para falar com eles em meu nome. Certificou-se de que o IAS continuava disposto a me receber e a conceder-me a bolsa pleiteada, e transmitiu de volta essa boa nova ao PAIGC em Dacar, que me passou a notícia. Compramos então novas passagens aéreas Dacar-Acra (ainda com a ajuda de minhas pequenas economias), e no aeroporto de Acra fomos recebidos por aquela representante do MPLA, que nos levou à Universidade de Gana e ao IAS. (Farias, 2010).

\section{No IAS, na Universidade de Gana}

O foco de Paulo Farias em Gana certamente estava relacionado com o fato de ser o primeiro país da África subsaariana a obter a independência em 1957, sob o comando de Kwame Nkrumah. O estadista apresentou um "projeto de constituição de um Estado Africano Continental e lançou um programa destinado a garantir a autonomia estratégica do continente" (Moore, 2010, p. 85). O país, centro do pan-africanismo, estimulava a independência dos demais países africanos e atraía outros olhares internacionais, a exemplo do Brasil, que o escolheu para instalar sua primeira embaixada na “África Negra”, enviando seu primeiro embaixador negro, Raymundo de Souza Dantas (Dantas, 1965; Dávila, 2011). Ả época, "uma nação muito especial" (Farias, 2007). Somem-se a isso o estimulante cenário acadêmico oferecido na Universidade de Gana e seu programa de mestrado no Instituto de Estudos Africanos, criado em 1962. Além de um curso de mestrado ser, à época, incomum na academia brasileira, aquele estava sob a direção do experiente historiador marxista inglês Thomas Hodgkin, que, antes

${ }^{6}$ Em 1961, o guineense Fidelis Cabral d'Almada, representante do PAIGC, chegou ao Brasil como estudante junto à primeira turma de estudantes africanos no Ceao (Dávila, 2011, p. 148-149; Reis, 2015, p. 46-47). 
de se dedicar ao estudo do Islã, já estava há mais de uma década envolvido nas questões colocadas pelo nacionalismo africano (Wolfers, 2007).

Contudo, os primeiros momentos de Paulo Farias em Gana não representaram a tranquilidade de que uma pessoa perseguida necessitava. Tanto na entrevista concedida em 2007 a Alberto da Costa e Silva quanto em 2010, para esta pesquisa, o professor menciona a tensão que a organização política em Gana lhe causou. Ao imaginar uma configuração política diferente da que havia vivido no Brasil, foi surpreendido com o autoritarismo do regime de Kwame Nkrumah: "isso me criou uma certa perturbação psicológica, semelhante à que sentia no Brasil" (Farias, 2010). Carlos Moore explica que Nkrumah, à semelhança de outros líderes no continente, acabou por erigir um governo ditatorial em função de estarem "acossados e permanentemente ameaçados de assassinato" (Moore, 2010, p. 85).

Por outro lado, a inquietação também podia estar relacionada com o fato de buscar em Gana um caráter não transitório, uma estabilidade domiciliar. Depoimentos de exilados da ditadura militar brasileira, registrados no livro organizado por Cavalcanti e Ramos (1976) ou na análise de Rollemberg (2007), revelam as angústias que essa permanente transitoriedade causava. Como se estabelecer em um lugar em que não se sabia por quanto tempo ficar ou em que não se queria ficar por muito tempo? Além das questões estruturais fundamentais, como casa e trabalho, nota-se que a marca do transitório era igualmente perturbadora e, talvez por isso, que a inserção em atividades que a pessoa gostasse de desempenhar fosse ao menos um alento para os que não podiam voltar para casa.

Essa referência à perturbação causada pela realidade política de Gana antecede, em ambas as entrevistas de Farias, as notas bastante elogiosas acerca da Universidade de Gana e de seu ambiente intelectual. Segundo nosso historiador, essa instituição, àquela época, foi a mais cosmopolita que já experimentou em toda a sua vida. Vejamos um fragmento de seu relato:

Mas Gana, que mantinha boas relações tanto com a União Soviética e seus aliados quanto com os Estados Unidos e seus aliados, incluiu naquela comissão gente que vinha de países e horizontes ideológicos diversos. Na comissão havia gente de orientação marxista bem como gente de orientação liberal não-marxista, professores de origem africana, norte-americana (uma americana branca e um afro-americano), britânica, e russa-soviética. [sic] [...] Essa orientação interétnica, pan-africanista, e intercontinental acima das divisões da Guerra Fria, dada ao IAS pelo regime de Nkrumah, iria criar vastas, e extremamente interessantes, perspectivas de aprendizado para mim quando ali cheguei em 1964. (Farias, 2010).

Esse estimulante ambiente intelectual experimentado por Farias na Universidade de Gana não foi registrado pelo embaixador Raymundo de Souza Dantas, designado para a embaixada brasileira em Acra, entre 1961 e 1965. Seu livro África difícil (missão condenada: diário) (1965) é um relato das contradições daquela experiência, cujo desafio era enfrentar 
"a diferença entre ser negro e ser africano, aliado com a questão de ser um homem negro cuja posição como representante do Brasil era criticada" (Dávila, 2011, p. 61). Na Universidade de Gana, cuja biblioteca utilizava todas as tardes para leitura, registrou uma questão levantada por um estudante acerca da inexistência da discriminação racial no Brasil. Tal pergunta, sem resposta imediata, deixou-o hesitante e reflexivo, uma vez que, como embaixador, tinha de enfrentar expressões de discriminação racial por parte do Itamaraty. A experiência de Dantas em Acra, oficial, financiada e designada pelo Estado, por diferentes motivos, não foi exitosa (Dávila, 2011, p. 59-68). Para Paulo Farias em fuga, buscando um vínculo para se manter em Gana e afastado do Brasil, foi a experiência acadêmica mais proveitosa.

O IAS foi instalado em Legon, subúrbio de Acra. Conforme assinala em sua página online, foi um dos primeiros centros no continente africano, "estabelecido nos anos do otimismo pós-colonial" e privilegiando metodologias centradas na África. ${ }^{7}$ Aquele ambiente de intensos debates e múltiplas possibilidades despertaria o jovem historiador brasileiro para desenvolver uma pesquisa centrada em um tema que não tivesse necessária relação com a história do Brasil. Rompia, assim, com a perspectiva, já citada anteriormente, de brasileiros que se interessavam pela história africana buscando entender o Brasil. Ao experimentar um ambiente intelectual diverso e estimulante na Universidade de Gana, Farias esclarece:

Nesse ambiente em que tanta coisa interessante acontecia, tantas ideias eram incessantemente debatidas, e tantos novos resultados de pesquisa sobre a história e as culturas da África eram constantemente apresentados, eu aprendia com sofreguidão. Fui percebendo que, para bem compreender as relações entre a África e o Brasil, não bastava estudar as regiões, e os períodos históricos, diretamente ligados a essas relações. Era preciso ir mais além, e estudar outras regiões e outras histórias africanas. Era preciso estudar a África como África, não como Brasil. (Farias, 2010).

Por uma espécie de "teimosia intelectual", optou por estudar a língua árabe entre os diversos cursos de línguas oferecidos no instituto e tomou o Islã como tema de pesquisa. Segundo Farias, os discentes eram encorajados a desenvolver temas originais com o máximo possível de fontes igualmente originais na tese a ser apresentada para a conclusão do curso. Sua atenção concentrou-se no movimento almorávida, "movimento islâmico surgido no século XI no Saara ocidental (atual Mauritânia), que dominou em seguida vastas regiões da África do Norte e da Espanha e Portugal" (Farias, 2010). Para tanto, necessitava de se deslocar para a Mauritânia, a fim de realizar a pesquisa. Sem recursos para tal deslocamento, Farias destaca que naquele momento foi auxiliado por Vincent Monteil.

Islamólogo e então diretor do Ifan, Monteil visitou a Universidade de Gana em 1965 para a realização de uma conferência sobre documentos históricos árabes. O experiente

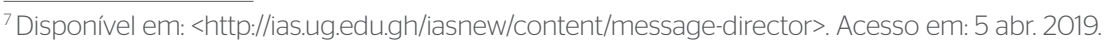


professor gostou do projeto de Farias e o convidou para participar de uma expedição que faria justamente para a Mauritânia, a fim de investigar vestígios arqueológicos com a participação de pesquisadores franceses, um pesquisador senegalês e outro mauritaniano. Essa experiência foi concretizada no início do ano 1966 e permitiu o trabalho de campo e o acesso aos arquivos naquele país, o qual foi considerado por ele uma "dádiva" (Farias, 2010) ou "essas felizes coincidências que acontecem na vida da gente" (Farias, 2007).

A tese que defendeu no IAS evidenciou uma dimensão intelectual do movimento almorávida e foi baseada em fontes arqueológicas e arquivistas: "textos medievais produzidos, fora da África Ocidental, por autores marroquinos e de outras partes da África do Norte, ou do Oriente Médio, ou da Andaluzia muçulmana". E acrescenta:

Até então os Almorávidas tinham sido vistos como um movimento de nômades ignorantes que pouco se interessavam por ideias. Mas, combinando uma nova análise dos documentos árabes com os resultados de nossa expedição arqueológica, foi-me possível mostrar que o movimento tinha uma dimensão intelectual muito importante. (Farias, 2010).

Essa pesquisa foi o início de seu trabalho com fontes escritas. Segundo Farias, a tese despertou interesse na universidade, tendo o Ifan publicado a tese (Farias, 1967). A biografia de Hodgkin faz referência a seu interesse pelo projeto quando deixou Gana (Wolfers, 2007). Anos depois, quando visitou a Mauritânia, descobriu que circulava uma tradução em árabe do texto, feita pela faculdade de letras da Universidade de Nouakchott (Farias, 2010).

Com a conclusão do mestrado, em meados de 1966, Farias necessitava de novo vínculo acadêmico para manter-se no continente africano. Nesse momento, foi contemplado com uma bolsa de pesquisa no Ifan. Para tal concessão, contou com alguma intervenção de Waldir Oliveira, que se mantinha atento a seus passos no exterior. De acordo com uma correspondência de Farias, Vincent Monteil mostrava-se sensibilizado pelo apoio que Waldir lhe oferecia, um perseguido político (Carta de Paulo Farias para Waldir Oliveira, Ceao, 20 nov. 1966). Dessa aproximação entre e o Ceao e o Ifan resultaram a publicação de um artigo de Monteil na Afro-Ásia, revista do Ceao, em 1967 (Monteil, 1967), a visita de Monteil à Bahia, em 1967 (Carta de Paulo Farias a Waldir Oliveira, Ceao, 1o out. 1967) e a ida do antropólogo do Ceao, Júlio Braga, para pesquisar no Ifan em 1968, com bolsa semelhante à de Farias (Reis, 2015).

\section{No Departamento de História, na Universidade Ahmadu Bello}

A estada por um ano para pesquisa em Dacar, no Senegal, propiciada pela bolsa do Ifan, foi a melhor alternativa para Farias imediatamente após a conclusão do mestrado (Carta de Paulo Farias para Waldir Oliveira, Ceao, ํo jul. 1966). No entanto, desde Acra, o historiador 
dialogava com Oliveira sobre as diversas possibilidades para sua manutenção no continente africano. Assim, pleiteava uma vaga no doutorado na Universidade de Birmingham, tentava a obtenção de passagens para seguir para a Europa por meio da Coordenação de Aperfeiçoamento de Pessoal de Nível Superior (Capes), cogitava uma vaga no doutorado na Universidade do Cairo e pensava em aceitar o convite para ensinar na Universidade Ahmadu Bello, em Zária, norte da Nigéria (Cartas de Paulo Farias para Waldir Oliveira, Ceao, o jul. 1966, 4 ago. 1966 e 20 nov. 1966). Após a instalação no Ifan, todos os contatos continuaram, inclusive com a remessa de documentos de Farias para Waldir e deste para as referidas instituições universitárias (Cartas de Paulo Farias para Waldir Oliveira, Ceao, 20 e 27 nov. 1966).

Na Nigéria, as atividades na Universidade Ahmadu Bello lhe apeteciam, por permitir que Farias continuasse no continente africano, recolhendo dados para a pesquisa. Essa universidade, em funcionamento desde 1962, era resultado do incentivo para a ampliação do ensino superior no país independente desde 1960 e havia incorporado em sua estrutura a Faculdade Ahmadu Bello de Estudos Árabes e Islâmicos. Em abril de 1967, escreveu a Waldir: "você [...] compreende que a ruptura dos meus contatos em que realizo pesquisas, antes de ter podido terminá-las e quanto tenho tantas lacunas a preencher, seria dolorosa e mesmo mutiladora" (Carta de Paulo Farias para Waldir Oliveira, Ceao, 28 abr. 1967). Segundo Paulo Farias, o convite para integrar o Departamento de História naquela universidade nigeriana deveu-se ao trabalho desenvolvido no Ifan. Ao assentir, começava, em fins de 1967, uma nova fase na vida do historiador como professor de história da África em uma "das grandes universidades africanas" (Farias, 2010).

Aquele era um Departamento que, sob a direção do professor Charles Smith (que, depois de sua conversão à religião islâmica, passaria a chamar-se Abdullahi Smith), era conhecido pelo notável trabalho que fazia: estava trazendo à tona todo um capítulo do passado da África Ocidental até então negligenciado pelos modernos Estudos Africanos (a história do grande movimento islâmico, chefiado por Osman Dan Fodio, que triunfara no norte da Nigéria nos começos do século 19). (Farias, 2010).

Data desse período a existência, no acervo do Ceao, de uma correspondência mais ativa entre seu diretor e o pesquisador africanista. Com o papel timbrado da universidade, Farias informava sobre a viagem até o norte da Nigéria, a instalação na nova universidade, a casa nova que ocupariam e o quarto que estaria reservado para o amigo, o primeiro a quem escrevia daquela localidade (Carta de Paulo Farias a Waldir Oliveira, Ceao, 8 out. 1967). Nessas cartas, trocadas entre outubro e 1967 e novembro de 1969, dois temas são os prioritários e recorrentemente abordados, a saber, o universo acadêmico na Nigéria e na Bahia e a vinculação de Farias com a UFBA.

Em relação à vida acadêmica, existem informações acerca das novas atividades a serem desenvolvidas na Universidade Ahmadu Bello, sobre os contatos com professores novos 
ou velhos conhecidos. Oliveira informava sobre o II Congresso de Africanistas, do qual participou com Costa Lima na cidade de Dacar em dezembro de 1967 (Carta enviada por Waldir Oliveira a Paulo Farias, Ceao, 3 jan. 1968), e sobre a produção acadêmica do Centro baiano com o andamento da revista Afro-Ásia (Carta enviada por Waldir Oliveira a Paulo Farias, Ceao, 11 set. 1968). Farias também recebeu um suplemento publicado no jornal A Tarde, organizado por Waldir Oliveira, relativo ao 80ำ aniversário da Abolição da Escravatura no Brasil (Carta enviada por Waldir Oliveira a Paulo Farias, Ceao, 20 maio 1968). Cogitavam, inclusive, a possibilidade de uma vinculação mais estreita entre ambas as universidades, uma vez que "Zária é um centro das melhores tradições da Nigéria do Norte no que diz respeito à erudição islâmica [...] um excelente lugar para estudo da cultura haussá" (Carta enviada por Paulo Farias a Waldir Oliveira, Ceao, 30 out. 1967).

Nessa fase, a correspondência estimulada por Farias permite a troca de informações atualizadas, tanto do que estava a realizar em Zária quanto do que era realizado no Centro baiano, estabelecendo uma dinâmica diferente em relação aos primeiros momentos no continente africano, quando evitava qualquer comunicação pessoal para não revelar sua localização: as cartas enviadas de Gana não continham o remetente. Naquele novo ambiente, em que se sentia um pouco mais seguro, já que a insegurança se tornava uma regra no exílio, Oliveira tornou-se um importante interlocutor para diálogo e atualização, abrandando o isolamento em que o historiador se encontrava, evitando que perdesse a dimensão do tempo e dos acontecimentos no Brasil, um dos dilemas enfrentados pelos exilados, conforme destacou Rollemberg (2007, p. 8).

Cabe destacar que Farias não se refere às dificuldades acadêmicas ou políticas na Nigéria, mesmo quando a própria Universidade Ahmadu Bello registra, em sua história, o desafio de se estabelecer em uma região cujo deficit educacional, após 60 anos de domínio colonial, resultava no baixo número de estudantes e professores nigerianos qualificados. ${ }^{8}$ Nacionalmente, a Nigéria vivenciava, entre 1967 e 1969, uma cruenta guerra após dois sucessivos golpes de Estado e a afirmação da independência política por parte do povo ibo — da República Independente de Biafra - , seguida de um massacre promovido pelo governo nigeriano. A Guerra de Biafra resultou em milhões de ibos mortos e teve ampla repercussão internacional (Falola e Heaton, 2008, p. 158-180).

Na correspondência trocada desde Zária, recebem maior atenção as informações acerca da vinculação de Farias com a UFBA em meio às alterações políticas e burocráticas vivenciadas pela universidade baiana e, consequentemente, pelo Ceao. A primeira correspondência existente em relação a essa fase data de 8 de outubro de 1967 e refere-se ao pedido de extensão de licença sem vencimentos. Desse modo, Paulo Farias continuava, mesmo estando fora do Brasil, vinculado à UFBA como professor assistente no Ceao. A manutenção da licença era a

$\overline{9}$ Ver o site da Universidade Ahmadu Bello. Disponível em: <https://abu.edu.ng/history.html>. Acesso em: 4 abr. 2019. 
garantia da manutenção de seu vínculo com a UFBA. E, ao que parece, Farias era estimulado a retornar à UFBA por dispor do diploma de mestrado, pela possibilidade de arquivamento dos processos e por Miguel Calmon ser o novo reitor (Cartas de Paulo Farias para Waldir Oliveira, Ceao, 28 abr. 1967). Em 30 de outubro de 1967, perguntava a Waldir se teriam, ele e Rena, (outra) oportunidade de trabalho na Bahia (Cartas de Paulo Farias para Waldir Oliveira, Ceao, 30 out. 1967). Em 2 e 3 de janeiro de 1968, seguem duas correspondências de Waldir, informando que havia sido concedida a licença por dois anos, e ao fim desse prazo seria necessário voltar para o trabalho na universidade (Cartas de Waldir Oliveira para Paulo Farias, Ceao, 2 e 3 jan. 1968).

Após o contato em janeiro de 1968 (Carta de Paulo Farias para Waldir Oliveira, Ceao, 17 jan. 1968), somente em setembro e outubro nova correspondência seria enviada por Farias, quando, a fim de "quebrar o silêncio", escreveu a Waldir Oliveira para informar acerca das férias em países do norte da África e da Europa, da qual haviam retornado e do novo curso que daria na Universidade Ahmadu Bello (Carta de Paulo Farias para Waldir Oliveira, Ceao, 11 set. 1968). A empolgação com as atividades da universidade nigeriana, informadas em setembro, não aplacava o desejo de retornar ao Brasil, informado na carta seguinte, em outubro (Carta de Paulo Farias para Waldir Oliveira, Ceao, 14 out. 1968). O professor mantinha-se estimulado pela possibilidade de arquivamento dos processos de que era alvo. Nesse texto, ponderou sobre os recursos disponíveis em maior quantidade nas universidades africanas, em oposição às dificuldades existentes na universidade brasileira, criticou o modo superior como o Brasil colocava-se diante do continente africano, mas o desejo era retornar: "Tudo bem pesado, creio que o que devemos mesmo fazer é regressar" (Carta de Paulo Farias para Waldir Oliveira, Ceao, 14 out. 1968).

Há cinco anos, estavam ele e a esposa fora do Brasil. Todas as experiências exitosas que Farias havia experimentado nas universidades africanas não arrefeciam seu interesse de voltar. Escreveria: "Mas também de vento vive o homem, e os ventos do Brasil continuam mais cariciosos aos meus ouvidos do que os ventos africanos, britânicos, gregos ou libaneses. E por mais amigos novos que façamos no exterior, a falta que sentimos dos de casa não desaparece" (Carta de Paulo Farias para Waldir Oliveira, Ceao, 14 out. 1968). Toda a tensa configuração política e universitária brasileira

[...] funciona como uma outra corrente que nos arrasta para aí, com a esperança (ou talvez a ilusão) de poder concorrer de algum modo para esse esforço, que vocês já vêm de há muito realizando no CEAO, de dar uma seriedade e produtividade maiores à nossa vida universitária. (Carta de Paulo Farias para Waldir Oliveira, Ceao, 14 out. 1968).

Em outubro de 1968, cumprindo a antecedência necessária, no início daquele semestre letivo, Farias informou oficialmente que não continuaria com o contrato na Universidade 
Ahmadu Bello. A impressão do abrandamento do regime político brasileiro, conforme discutia na correspondência com Waldir Oliveira, seria completamente esfacelada com a proclamação do Ato Institucional no 5 (AI-5), em 13 de dezembro de 1968, que marcou o início dos anos mais repressivos da ditadura civil-militar no Brasil. No depoimento, Farias relata: "Nosso plano de retorno ao Brasil tornou-se inviável. Isso ficou mais claro ainda em maio de 1969, quando fui demitido da UFBA sem direito a indenização ou pensão" (Farias, 2010).

Em 10 de abril de 1969, Waldir transcreveu a Farias o ofício da Reitoria da UFBA, publicado no dia 2 daquele mês, obrigando-o a regressar à universidade em 30 dias, orientação que, caso não fosse cumprida, resultaria na aplicação de penas, conforme a legislação em vigor (Carta de Paulo Farias para Waldir Oliveira, Ceao, 10 abr. 1969). A penalidade foi a exoneração comunicada, "muito a contragosto", em 27 de maio de 1969, em correspondência de Waldir para Farias (Ceao). ${ }^{9}$ Certamente, os meses iniciais de 1969 foram bastante incertos para Farias, que perdia simultaneamente os dois vínculos universitários que tinha, na Nigéria e no Brasil. Em relação à desvinculação na Bahia, Waldir registrou: “continuamos a lamentar profundamente que o nosso Centro tenha perdido um especialista como você, talvez o único especialista brasileiro em História da África" (Carta de Waldir Oliveira a Paulo Farias, Ceao, 4 nov. 1969).

\section{No Centre of West African Studies, na Universidade de Birmingham}

O contato entre Paulo Farias e a Universidade de Birmingham datava de 1966, quando pleiteava uma vaga no curso de doutorado. Nessa universidade, localizada na cidade homônima, próximo a Londres, capital da Inglaterra, Farias interessava-se pelo Centre of West African Studies. Jonh Fage, fundador e diretor do referido Centro, quando consultado por Oliveira, havia demonstrado interesse na candidatura do historiador brasileiro, mas questionava qual instituição arcaria com os custos (Cartas de Jonh Fage para Waldir Oliveira, Ceao, 17 fev. 1966 e 16 mar. 1966).

Nova oportunidade surgiria em meados de 1969, quando abriu uma vaga para professor nesse Centro inglês. Farias candidatou-se, logrando o êxito de ser selecionado em detrimento de candidatos ingleses (Farias, 2010). Ả época, sem vínculo acadêmico no continente africano e impossibilitado de voltar ao Brasil, Farias explica que "se candidatou a diversos postos de trabalho pelo mundo" e "quase foi parar na Jamaica" (Gallas, 2014). A vaga ocupada em Birmingham foi possível após uma mudança no cenário acadêmico norte-americano, que, ao se interessar pela cultura africana, contratou o antecessor de Farias, abrindo uma vaga

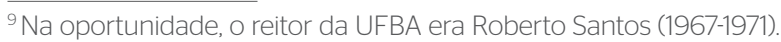


(Gallas, 2014). A correspondência com Waldir para esse período finaliza exatamente quando o cumprimentava pelo ingresso como professor na instituição inglesa.

São as cartas trocadas entre Farias e Verger, existentes na FPV, que podem oferecer informações acerca dos primeiros anos da vida de Farias na Europa. Trata-se de um volume de cartas que abarcam prioritariamente os anos entre 1969 e $1973 .{ }^{10}$ A correspondência revela a inquietude dos últimos dias antes da partida para a Europa e os primeiros anos na instituição inglesa. Farias solicitou a compra de vários adirês ${ }^{11}$ e pediu que os entregasse ao pai de Rena em Salvador, pois estavam saindo do continente africano e não teriam mais como comprá-los (Carta de Paulo Farias para Pierre Verger, FPV, 4 ago. 1969). Já instalado, trocaram informações sobre livros e outros textos, que Farias remeteu a Verger na Bahia (Carta de Paulo Farias para Pierre Verger, FPV, 24 jun. 1970). Verger solicitou um livro (Carta de Pierre Verger para Paulo Farias, FPV, 6 maio 1971), que Farias encomendou imediatamente e remeteu dois meses depois (Cartas de Paulo Farias para Pierre Verger, FPV, 19 maio 1971 e 2 jul. 1971). Verger fez questão de pagar o livro e também enviou um texto de sua autoria (Cartas de Paulo Farias para Pierre Verger, FPV, 6 set. 1971 e 5 out. 1972).

Um aspecto interessante apontado nessa correspondência é que a presença do historiador na Inglaterra coincidiu com a de outros brasileiros que igualmente não podiam estar no Brasil. Havia outros exilados em função do regime político brasileiro. Em 12 de dezembro de 1970, Farias escreveu ao "caro Pierre", na Bahia, buscando recomendações de artistas nigerianos que indicaria a Gilberto Gil, que residia em Londres e "queria ir à África" (Carta de Paulo Farias para Pierre Verger, FPV, 12 dez. 1970). Essa correspondência revela o interesse do historiador em ressaltar como a África era importante matriz civilizatória que deveria inspirar os brasileiros, considerações à época incomuns no Brasil.

Naqueles primeiros anos na universidade inglesa, Verger foi um importante interlocutor, com o qual Farias pôde atualizar-se em relação ao cenário acadêmico brasileiro, compartilhar suas descobertas e impressões do cenário acadêmico inglês, além de buscar palavras amigas, para abrandar as angústias que o afligiam naquele contexto, que, a despeito de sua aparente acomodação, continuavam marcadas pelo incômodo da condição de exilado. Foi nesse momento que fez sua consulta ao Ifá. Em 1972, já contava uma década de pesquisa em história da África, e a proeminente trajetória acadêmica que descrevia não era suficiente para aplacar a contínua sensação de insegurança de quem não podia escolher retornar. Havia de escolher caminhos e encontrar a paz possível em qualquer lugar do mundo, África ou Europa, e transformá-lo em casa. A sensação de transitoriedade fazia-se insistente, além de outras aflições, que só o próprio professor poderia descrever.

${ }^{10}$ Nesse volume de cartas, registro duas exceções: a primeira e a última carta, ambas enviadas por Paulo Farias a Pierre Verger. A primeira data de 1962, e a última, de 1987 (FPV).

"Tradicionais tecidos iorubás feitos com diferentes técnicas de tingimento. 
Aúltima correspondência de sua autoria guardada por Fatumbi, cinco páginas datilografadas, foi enviada após um intervalo de 14 anos, em 4 de agosto de 1987 (FPV). Pierre Verger, já com quase 85 anos de idade, recebeu a carta em sua residência em Salvador, já que não realizava mais as frequentes viagens de pesquisa para o exterior. ${ }^{12}$ Nesse tempo, muita coisa havia acontecido. Farias, então com 50 anos de idade, manteve-se na Universidade de Birmingham e, uma vez separado de Rena Martins, casou-se com Karin Barber. O historiador manteve sua pesquisa com foco em aspectos históricos do islamismo no continente africano, com visitas regulares a países da África Ocidental, especialmente ao Mali, para trabalho de campo. Já havia iniciado seu trabalho com fontes epigráficas (estudos de inscrições em pedra nas línguas árabe ou berbere em antigos sítios arqueológicos), as quais, somadas às fontes orais e escritas, seriam analisadas por longo tempo e resultariam no premiado livro publicado em 2003: Arabic medieval inscriptions from the Republic of Mali: epigraphy, chronicles, and Songhay-Tuāreg History (Farias, 2003a). O livro tem repercutido entre pesquisadores brasileiros estudiosos do tema (Mota, 2016).

Em 1987, o Brasil vivia seus primeiros anos democráticos, após 21 anos de regime ditatorial. Essa última correspondência enviada a Verger foi motivada pela saudade. O texto ao "senhor professor mestre" faz um histórico do diálogo nutrido entre os dois pesquisadores ao longo dos anos e relembra correspondências, livros e notas que trocaram, os encontros e desencontros que viveram, sobretudo entre o final dos anos 1960 e o início de 1970. Por meio desse texto, Farias conta como, nos últimos anos, mesmo sem correspondência constante, recebia notícias de Verger por amigos ou conhecidos em comum de passagem pela Inglaterra, caso do historiador João José Reis, que passava o ano por lá. Relembra a visita realizada a Verger em sua casa, na Bahia, em "1982 ou 1983", revelando que já havia estado no Brasil quase 20 anos após ter saído. O texto não se detém nessa lembrança do reencontro de Farias com seu amigo, com sua cidade natal, seu país.

$\mathrm{O}$ amigo em comum que recebeu maior destaque na missiva foi Olabiyi Yai. O linguista beninense, com larga experiência como pesquisador visitante ou consultor em línguas africanas pela Organização das Nações Unidas para a Educação, a Ciência e a Cultura (Unesco) em diferentes países, incluindo o Brasil, era amigo de longa data de Verger. Quando Farias escrevia sua carta, Yai estava novamente arrumando suas malas, após ter estado durante um semestre em Birmingham. Yai havia atualizado Farias com informações sobre Verger. Os sentimentos pela partida do querido colega eram a motivação inicial para o envio dessa carta. Conforme escreveu, ao ter de viver a dor da despedida de um amigo em comum, o ato de escrever era uma maneira de reviver a alegria do encontro:

Querido Pierre [...] Escrevo muito pouco, mesmo para as pessoas que eu mais respeito e estimo. Mas hoje estou triste [...] então achei que, para tratar a

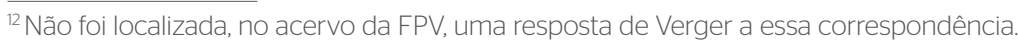


saudade antecipada de um amigo que vai viajar, o melhor remédio é escrever para outro amigo de quem também tenho saudade. (Carta de Paulo Farias para Pierre Verger, FPV, 4 ago. 1987).

A carta, cheia de lembranças dos idos tempos a respeito de amigos com os quais não mais se correspondia regularmente, bem como de notícias de publicações e notas de pesquisa, revelava um pesquisador maduro, diante de um de seus mestres, lembrando com saudade e tranquilidade os encontros e desencontros da vida. Seu exílio africano foi um imperativo que o colocou diante de experiências que acabaram por mudar e marcar radicalmente sua trajetória de vida. O historiador parecia ter se apaziguado com seu passado que rememorava, assim como nas entrevistas que concedeu mais recentemente, sem nutrir dores ou angústias. Será que fez jus às considerações do velho babalaô?

A autora agradece a Paulo Farias e Angela Luhning. 


\section{Referências bibliográficas}

AGOSTINHO, Pedro. Agostinho da Silva. Pensamento à solta: um manuscrito autógrafo. Salvador: EDUFBA, 2006.

ARNS, D. Paulo Evaristo (Coord.). Brasil: nunca mais. 16. ed. Petrópolis: Vozes, 1986.

BOURDIEU, Pierre. A ilusão biográfica. In: FERREIRA, Marieta Moraes; AMADO, Janaina (Org.). Usose abusos da história oral. Rio de Janeiro: FGV, 2002.

BRITO, Antonio Maurício Freitas. O golpe de 1964, o movimento estudantil na UFBA e a resistência à ditadura militar (1964-1968). 2008. Tese (Doutorado em História Social), Universidade Federal da Bahia, Salvador, 2008.

CARTAS de Pierre Verger a Vivaldo da Costa Lima. Afro-Ásia, Salvador, n. 37, p. 241-288, 2007.

CASTRO, Yêda Pessoa de. Falares africanos no Bahia (umvocabulário afro-brasileiro). Rio de Janeiro: Topbooks, 2001.

CAVALCANTI, Pedro Celso Uchôa; RAMOS, Jovelino (Org.). De muitos caminhos. São Paulo: Livramento, 1976. Coleção Memórias do Exílio, Brasil 1964-19--

DANTAS, Raymundo Souza. África difícil (missão condenada - diário). Rio de Janeiro: Leitura, 1965.

DÁVILA, Jerry. Hotel trópico: o Brasil e o desafio da descolonização africana (1950-1980). Rio de Janeiro: Paz e Terra, 2011.

DEPELCHIN, Jacques. Silences in African history: between syndromes of discovery and abolition. Dar es Salaam: Mkuki na Nyota, 2005.

FAGE, John. Ghana: a historical interpretation. Madison, Wisconsin: University of Wisconsin Press, 1959.

FALOLA, Toyin; HEATON, Matthew. Instalility and civil war, 1960-1970. In: A history of Nigeria. Nova York: Cambridge University Press, 2008. p. 158-180.

FARIAS, Paulo Fernando de Moraes. Arabic medieval inscriptions from the Republic of Mali: epigraphy, chronicles, and Songhay-Tuāreg history. Oxford; Nova York: Oxford University Press for The British Academy, $2003 a$.

Enquanto isso, do outro lado do mar... os Arokine a identidade iorubá. Afro-Ásia, Salvador, n. 17, p. 139155, 1996.

John Donnelly Fage 1921-2002. Sudanic Africa, n. 14, p. 1-7, 2003b.
Oranmiyan's frustrated war on Mecca: reflexes of Borgu ritual in Johnson's yoruba narratives. In: FALOLA, Toyin (Coord.). Pioneer, patriot and patriarch: Samuel Johnson and the yoruba people. Madison: African Studies Program, University of WisconsinMadison, 1993. p. 121-132.

The Almoravids: some questions concerning the character of the movement. Bulletin de l'IFAN, Dakar, série B, v. 29, n. 3-4, p. 794-878, 1967.

FERREIRA, Muniz Gonçalves. O golpe de Estado de 1964 na Bahia. Palestra, 2004. Disponível em: 〈http:// www.fundaj.gov.br/licitacao/observa_bahia_02.pdf>. Acesso em: 26 set. 2018.

FERREIRA, Roquinaldo. A institucionalização dos estudos africanos nos Estados Unidos: advento, consolidação e transformações. Revista Brasileira de História, São Paulo, v. 30, n. 59, p. 73-90, 2010.

GASPARI, Elio. A ditadura escancarada: as ilusões armadas. São Paulo: Companhia das Letras, 2002.

GREEN, James. Exilados e acadêmicos: a luta pela anistia nos Estados Unidos. Cadernos AEL, Campinas, v. 17, n. 29, p. 295-312, set. 2010.

HOUNTONDJI, Paulin. Conhecimento de África, conhecimento de africanos: duas perspectivas sobre os estudos africanos. Revista Crítica de Ciências Sociais, n. 80, p. 149-160, mar. 2008.

JOHNSON, Samuel. The history of yorubas: from the earliest times to the beginning of the British Protectorate. Edição de Obadiah Johnson. Cambridge: Cambridge University Press, 2010.

LIMA, Vivaldo da Costa. A família de santo nos candomblés jeje-nagôs da Bahia: um estudo de relações intragrupais. 2. ed. rev. Salvador: Corrupio, 2003.

LÜHNING, Angela. Pierre Fatumbi Verger e sua obra. Afro-Ásia, Salvador, v. 21-22, p. 315-353, 1998-1999.

MACAMO, Elísio. Respostas sem perguntas ou: porque a África não é um problema por resolver. In: EVORA, Iolanda; FRIAS, Sónia (Coord.). In: In Progress. 2o Seminário sobre Ciências Sociais e Desenvolvimento em África. Lisboa: Centro de Estudos sobre África e do Desenvolvimento, 2016. p. 225-264.

MENESES, Adolpho Justo Bezerra de. O Brasil e o mundo ásio-africano. 2. ed. Rio de Janeiro: GDR, 1960. 
MONTEIL, Vincent. O Islão na África Negra. AfroÁsia, Salvador, n. 4-5, p. 5-23, 1967.

MOORE, Carlos. A África que incomoda: sobre a problematização do legado africano no quotidiano brasileiro. Belo Horizonte: Nandyala, 2010.

MOTA, Thiago Henrique. Sobre o Alcorão e por Maomé: Islã, produção intelectual e capital cultural na Senegâmbia (séculos XVI e XVII). In: REIS, Raissa; GARRIDO DE REZENDE, Taciana; MOTA, Thiago Henrique (Org.). Diálogos sobre África Ocidental: dinâmicas culturais, diálogos transatlânticos. Curitiba: Prismas, 2016.

MOTTA, Rodrigo Patto Sá. As universidades e o regime militar: cultura política brasileira e modernização autoritária. Rio de Janeiro: Zahar, 2014.

REIS, Luiza. De improvisados a eméritos: trajetórias de intelectuais no Centro de Estudos Afro-orientais (1959-1994). 2015. Tese (Programa Multidisciplinar em Estudos Étnicos e Africanos) - Faculdade de Filosofia e Ciências Humanas, Universidade Federal da Bahia, Salvador, 2015.

ROLLEMBERG, Denise. Entre raízes e radares, o exílio brasileiro (1964-1979). In: XI JORNADAS INTERESCUELAS. Anais... San Miguel de Tucumán: Departamento de Historia, Facultad de Filosofía y Letras, Universidad de Tucumán, 2007. Disponível em: 〈http://cdsa.aacademica.org/000-108/758.pdf〉. Acesso em: 26 set. 2018.
SILVA, Amândio; AGOSTINHO, Pedro (Org.). Presença de Agostinho da Silva no Brasil. Rio de Janeiro: Casa de Rui Barbosa, 2007.

SURET-CANALE, Jean. L'Afrique Noire Occidentale et Centrale. Paris: Éditions Sociales, 1958.

WOLFERS, Michael. Thomas Hodgkin: Wandering Scholar - a biography. Monmouth: Merlin Press, 2007.

YANKELEVICH, Pablo. Estudar o exílio. In: QUADRAT, Samantha Viz (Org.). Caminhos cruzados: história e memória dos exílios latino-americanos no século XX. Rio de Janeiro: FGV, 2011.

\section{Arquivos consultados}

Acervo do Ceao.

Fundação Pierre Verger.

\section{Entrevistas}

FARIAS, Paulo Fernando de Moraes. Decifrando a África. Entrevista concedida a Alberto da Costa e Silva. Revista de História da Biblioteca Nacional, n. 26. 2007. Entrevista concedida a Luiza Reis. 2010.

GALLAS, Daniel. "Na África, voltei a ser cidadão", conta exilado brasileiro em 1964. BBC Brasil em Londres, lo abr. 2014. Disponível em: 〈http://www.bbc.com/ portuguese/noticias/2014/04/140331_depoimento_ farias_dg〉. Acesso em: 25 maio 2018. 